\title{
Ensino de Sílabas Simples, Leitura Combinatória e Leitura com Compreensáo para Aprendizes com Autismo ${ }^{1}$ Teaching Simple Syllables, Combinatorial Reading and Comprehension READING FOR LEARNERS WITH AUTISM
}

\author{
Camila Graciella Santos GOMES ${ }^{2}$ \\ Deisy das Graças DE SOUZA ${ }^{3}$
}

\begin{abstract}
RESUMO: crianças com autismo podem apresentar dificuldades em aprender habilidades de leitura. O estudo, com o objetivo de avaliar o ensino de leitura oral e de leitura com compreensão, contou com a participação de três meninos com autismo, não alfabetizados, com idades entre cinco anos e nove meses e nove anos e nove meses, falantes e estudantes de escolas comuns. $\mathrm{O}$ procedimento, dividido em seis conjuntos de ensino, consistiu no ensino direto de nomeaçáo de sílabas simples e no ensino de nomeação de figuras, com o intuito de estabelecer leitura combinatória com compreensão, ou seja, a habilidade de ler oralmente e de compreender palavras composta por sílabas simples, a partir da combinaçâo das sílabas ensinadas e da formação de classes de estímulos equivalentes. Os participantes foram avaliados em relação à nomeação de letras, sílabas, palavras e compreensão de leitura (relação entre figuras e palavras impressas) antes e após cada conjunto de ensino. Os dados foram analisados individualmente, comparando-se o desempenho de cada participante antes e após o ensino. Os resultados indicaram que o procedimento utilizado favoreceu a aprendizagem e a manutenção da leitura combinatória com compreensão, com poucas sessões de ensino e com baixo número de erros durante o processo.
\end{abstract}

PALAVRAS-CHAVE: Educação Especial. Autismo. Ensino de Leitura.

\begin{abstract}
Children with autism may have difficulty in learning reading skills. The study, with the purpose to evaluate the teaching of oral reading and reading comprehension, was conducted with three boys with autism, illiterate, aged five years and nine months and nine years and nine months, speakers and students from regular schools. The procedure was divided into six teaching sets and consisted of the direct teaching of naming simple syllables and the teaching of naming pictures, with the purpose of establishing combinatorial reading and comprehension reading; in other words, the purpose was to teach the ability to read orally and to understand words composed of simple syllables, from the combination of taught syllables and the formation of stimulus equivalence classes. Participants were evaluated for naming letters, syllables, words and reading comprehension (relationship between pictures and printed words) before and after each set of teaching. Data were analyzed individually by comparing the performance of each participant before and after the instruction. The results indicated that the procedure favored the learning and maintenance of combinatorial reading with understanding, with few teaching sessions and low number of errors during the process.
\end{abstract}

KEYWORDS: Special Education. Autism. Teaching Reading.

\section{INTRODUÇÃo}

Aprendizes com autismo, caracterizados por alterações sociais e de comunicação e por interesses restritos, fixos, intensos e comportamentos repetitivos (AMERICAN PSYCHIATRIC ASSOCIATION, 2013), podem apresentar dificuldades em aprender habilidades de leitura.

\footnotetext{
${ }^{1}$ http://dx.doi.org/10.1590/S1413-65382216000200007
}

Nota dos autores: o estudo fez parte da tese de doutorado da primeira autora, que contou com bolsa do CNPq. A segunda autora é bolsista de Produtividade em Pesquisa do CNPq e membro do Instituto Nacional de Ciência e Tecnologia sobre Comportamento, Cognição e Ensino, financiado pelo CNPq (Processo \#573972/2008-7) e pela FAPESP (Processo \# 2008/57705-8), que apoiou a redação do manuscrito

${ }^{2}$ Doutora em Educação Especial, Diretora do CEI Desenvolvimento Humano e Docente da Faculdade de Ciências Médicas de Minas Gerais. Belo Horizonte, MG, Brasil. camila.gomes@ceidesenvolvimentohumano.com.br

${ }^{3}$ Doutora em Psicologia, Docente do Programa de Pós-Graduação em Educação Especial - Universidade Federal de São Carlos. Centro de Educação e Ciências Humanas. Laboratório de Estudos do Comportamento Humano. São Carlos, SP - Brasil. deisydesouza@gmail.com 
Segundo Nation et al. (2006) há duas perspectivas diferentes na literatura a respeito dessa aprendizagem: a primeira considera que o repertório pobre de habilidades de linguagem, típico do quadro de autismo, coloca esses indivíduos em grande risco de fracasso na aprendizagem desse conteúdo. A segunda descreve, em diversos estudos de caso, sucessos no ensino de leitura a pessoas com autismo, embora os pesquisadores salientem a necessidade de se ter cuidado com a generalização dos resultados de estudos de caso com essa população, especialmente pela ampla variabilidade no repertório de habilidades cognitivas e de linguagem observada entre as pessoas com autismo.

Detalhando um pouco melhor as pesquisas sobre as características da leitura dessa população, parece haver um consenso nos estudos em afirmar que, quando essas pessoas aprendem a ler, há uma diferença importante no desempenho delas no que se refere à leitura oral do texto (resposta vocal sob controle de palavra impressa, sem necessariamente compreender o que está escrito nele) e à leitura com compreensáo (que exige necessariamente o entendimento do conteúdo expresso no texto); os estudos apontam, com unanimidade, melhores desempenhos na leitura oral do que na compreensão do texto (GRIGORENKO et al., 2002; NATION et al., 2006; O'CONNOR; KLEIN, 2004). De maneira geral, os estudos indicam problemas na leitura de pessoas com autismo, pois um leitor eficiente deve ser capaz de ler oralmente e de compreender aquilo que lê (ADAMS, 1994).

Seguindo as indicaçóes da literatura, procedimentos planejados para o ensino de leitura para pessoas com autismo deveriam considerar estratégias que favoreçam tanto a leitura oral quanto a leitura com compreensão.

A leitura oral fluente pode ser definida como leitura combinatória(HANNA et al., 2010; MUELLER; OLMI; SAUNDERS, 2000), que consiste na habilidade de ler qualquer palavra (não apenas palavras diretamente ensinadas) sob controle de unidades intra-palavras (DE ROSE; DE SOUZA; HANNA, 1996) e/ou intra sílabas (MUELLER; OLMI; SAUNDERS, 2000); assim, procedimentos que enfoquem o ensino de sílabas podem favorecer a aprendizagem desse aspecto da leitura (ALVES et al., 2007; DE SOUZA et al., 2009).

A leitura com compreensão pode ser identificada quando o aprendiz relaciona o que lê com aspectos do mundo e de sua experiência prévia com eles. Em tarefas de avaliação, esse aspecto da leitura pode ser verificado quando um aprendiz relaciona corretamente figuras às palavras impressas correspondentes, assim como o inverso, e a aprendizagem desses comportamentos ocorre de maneira indireta, derivada de relaçóes entre estímulos (ex. palavra ditada-palavra impressa; palavra ditadafigura) ou entre estímulos e respostas (ex. nomeação de palavra impressa; nomeação de figura) previamente aprendidas. Quando esses estímulos (figuras e palavras) se tornam equivalentes, ou seja, quando passam a fazer parte de uma mesma classe, pode-se dizer que o indivíduo compreende o que lê (SIDMAN, 1994). Procedimentos de ensino fundamentados no paradigma da equivalência de estímulos podem engendrar a aprendizagem de leitura com compreensão (DE ROSE; DE SOUZA; HANNA, 1996).

O objetivo desse estudo, interessado na aprendizagem de leitura de indivíduos com autismo, é verificar os efeitos de um procedimento de leitura, que envolveu o ensino direto de nomeação de sílabas e o ensino de nomeação de figuras, com o intuito de estabelecer leitura combinatória com compreensão, ou seja, a habilidade de ler oralmente e de compreender palavras composta por sílabas simples, a partir da combinação das sílabas ensinadas (ALVES et al., 2007; DE SOUZA 
et al., 2009; MUELLER; OLMI; SAUNDERS, 2000; SEREJO et al., 2007) e da formação de classes de estímulos equivalentes (SIDMAN, 1994).

\section{Método}

\section{1 Participantes}

A seleção dos participantes considerou os seguintes critérios: diagnóstico prévio de autismo realizado por médico especializado, presença de fala (condição para a nomeação de palavras e figuras), não ser alfabetizado (não ser capaz de ler oralmente palavras de sílabas simples, do tipo consoante-vogal) e idade cronológica a partir de cinco anos. Participaram do estudo três meninos (Quadro 1), estudantes de escolas comuns, que incialmente foram avaliados pela Childhood Autism Rating Scale - CARS (SCHOPLER; REICHLER; RENNER, 1988), pelo Psychoeducational Profile-Revised- PEP-R (SCHOPLERet al., 1990) e pelo Assessmentof Basic Learning Skills- ABLA (KERR et al., 1977).

\begin{tabular}{lcccccc}
\hline \multirow{2}{*}{ Participante } & \multirow{2}{*}{ Idade } & \multicolumn{2}{c}{ CARS } & \multicolumn{2}{c}{ PEP-R } & \multirow{2}{*}{ ABLA } \\
\cline { 3 - 6 } & & Pontuaçáo & Classificaçáo & Pontuaçáo & Idade & \\
\hline P1 & $9 a 9 \mathrm{~m}$ & 33 & leve/moderado & 105 & $4 \mathrm{a}$ & 6 \\
P2 & 6a & 36,5 & leve/moderado & 101 & $3 \mathrm{a} 10$ & 6 \\
P3 & 5a 9m & 30 & leve/moderado & 109 & 4a 3m & 6 \\
\hline
\end{tabular}

Quadro 1 - Características Gerais dos Participantes

Fonte: elaboração própria

A CARS permite identificar crianças com características comportamentais de autismo e distinguir entre autismo e atraso no desenvolvimento sem autismo. De acordo com a escala, os resultados da avaliação podem ser distribuídos em três categorias: desenvolvimento normal (15-29,5), autismo leve/moderado (30-36,5) e autismo grave (acima de 37). O PEP-R avalia tanto atraso no desenvolvimento como comportamentos típicos de autismo e a pontuação total da Escala de Desenvolvimento permite comparar, em anos e meses, o desenvolvimento da criança avaliada ao de uma criança típica. Tanto a CARS quanto o PEP-R foram adaptados e validados para a população brasileira (PEREIRA; RIESGO; WAGNER, 2008; LEON et al., 2005). O ABLA avalia o repertório discriminativo em seis níveis crescentes de complexidade; imitação (Nível 1), discriminação simples de posição (Nível 2), discriminação simples visual (Nível 3), discriminação condicional visual-visual (Nível 4), discriminação simples auditiva (Nível 5) e discriminação condicional auditivo-visual (Nível 6).

Os participantes apresentavam autismo leve/moderado, de acordo com os critérios da CARS, estavam no nível seis do ABLA e desenvolvimento abaixo do que era esperado para a idade cronológica, de acordo com a Escala de Desenvolvimento do PEP-R; apesar da diferença na idade cronológica todos apresentaram pontuação próxima a correspondente a quatro anos de idade.

Tanto o recrutamento dos participantes quanto os demais procedimentos empregados no estudo foram aprovados pelo Comitê de Ética em Pesquisa em Seres Humanos da Universidade Federal de São Carlos, para um projeto mais amplo de ensino de relaçóes condicionais a pessoas com autismo (Parecer número 044/2008). 


\subsection{Situação E Materiais}

As sessões experimentais foram realizadas em uma sala com poucos estímulos, mobiliada com uma mesa, duas cadeiras e uma filmadora. A mesa ficava encostada em uma parede, o participante sentava-se de frente para esta e a pesquisadora permanecia atrás dele. As sessóes tinham duração aproximada de 50 minutos e eram realizadas uma vez por semana.

Os seguintes materiais foram utilizados para cada um dos participantes: caderno sem pauta; canetinhas (vermelhas, pretas e azuis); figuras de $10 \mathrm{~cm} \times 10 \mathrm{~cm}$; palavras impressas digitadas em letras maiúsculas do tipo Arial, tamanho 72; bases de papel calandrado de $10 \mathrm{~cm}$ x $15 \mathrm{~cm}(\mathrm{LxA})$; divisórias de fichário (páginas); fichário e velcro.

\subsection{Procedimentos}

A Figura 1 apresenta um diagrama esquemático da rede de relaçóes condicionais envolvidas no estudo. As relaçóes diretamente ensinadas foram: C-D (nomeação de palavra impressa) e B-D (nomeaçáo de figura). As relaçôes verificadas em testes foram: B-C (figura-palavra impressa), C-B (palavra impressa-figura), A-B (palavra ditada-figura; identificação de figura) e A-C (palavra ditada - palavra impressa; identificação de palavra impressa). Além das relaçóes testadas que faziam parte da rede, foram realizadas sondas de nomeaçáo oral de palavras novas, compostas por sílabas recombinadas das palavras ensinadas (leitura recombinativa).

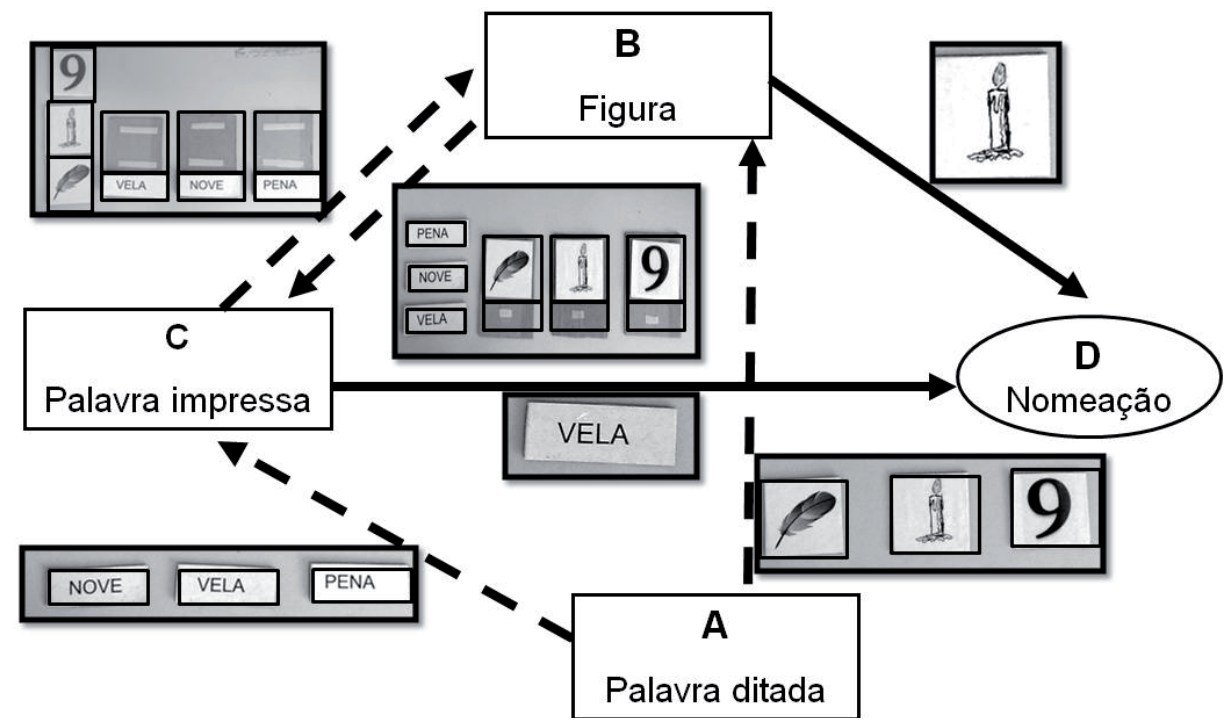

Figura 1 - Diagrama esquemático da rede de relações condicionais envolvidas no procedimento utilizado.

Fonte: elaboração própria

Descriçáo da Figura 1: as setas partem do conjunto dos estímulos modelo para o conjunto dos estímulos de comparação (ambos representados pelos retângulos) ou para uma classe de respostas (representada pelaelipse). Setas com linhas cheias representam desempenhos ensinados 
(C-D e B-D). Setas com linhas tracejadas representam desempenhos verificados nos testes (B-C, C-B, A-B e A-C).

\subsection{ENSINO DE NOMEAÇÃO DE PALAVRAS IMPRESSAS E DE FIGURAS}

O ensino de nomeação de palavras impressas (C-D) ocorreu por meio do ensino direto de sílabas simples e regulares, do tipo consoante-vogal. As sílabas foram divididas em seis conjuntos silábicos: Conjunto $1(\mathrm{t}, \mathrm{l}, \mathrm{m})$; Conjunto 2 (f, b, r); Conjunto 3 (p, n, v); Conjunto 4 (s, d, j); Conjunto 5 (x e z); Conjunto 6 (c e g) ${ }^{4}$. Cada conjunto silábico era composto por dois (5 e 6$)$ ou três $(1,2,3$ e 4$)$ grupos silábicos.

O ensino dos grupos silábicos era realizado em três etapas sequenciais, nas quais os participantes executavam: 1) tentativas de nomeação de sílabas e de palavras, escritas a canetinha, em caderno, pela pesquisadora; 2) tentativas de emparelhamento multimodelo por identidade, em fichário, com as palavras impressas ensinadas anteriormente no caderno; 3) nomeação oral das figuras selecionadas para os testes do conjunto silábico treinado (os testes serão explicados a seguir). O Quadro 2 apresenta os estímulos utilizados nas três etapas de ensino.

\begin{tabular}{|c|c|c|c|c|}
\hline Conjuntos & Grupos & Palavras: caderno e fichário & $\begin{array}{l}\text { Figuras e palavras: } \\
\text { testes }\end{array}$ & Recombinação \\
\hline \multirow{3}{*}{$\mathrm{T}, \mathrm{L}, \mathrm{M}$} & $\mathrm{T}$ & tatu, teto, ti, tutu, tio, iate & \multirow{3}{*}{$\begin{array}{l}\text { lua, mola, tatu, tela, } \\
\text { tomate, mato }\end{array}$} & \multirow{6}{*}{$\begin{array}{l}\text { moto, muito, lima, } \\
\text { remo, batata, fita, tabe } \\
\text { la, fubá, rua, abalou }\end{array}$} \\
\hline & $\mathrm{L}$ & luta, lei, tela, leite, lua, lata & & \\
\hline & M & $\begin{array}{l}\text { mola, mato, tomate, mala, meia, } \\
\text { muleta }\end{array}$ & & \\
\hline \multirow{3}{*}{$\mathrm{F}, \mathrm{B}, \mathrm{R}$} & $\mathrm{F}$ & fila, fome, mofo, folia, fatia, família & \multirow{3}{*}{$\begin{array}{l}\text { fila, bola, bife, baleia, } \\
\text { rato, rio }\end{array}$} & \\
\hline & B & bola, baú, bife, bateu, bela, baleia & & \\
\hline & $\mathrm{R}$ & rato, rio, rima, rifa, rabo, rolo & & \\
\hline \multirow{3}{*}{$\mathrm{P}, \mathrm{N}, \mathrm{V}$} & $\mathrm{P}$ & pato, mapa, apito, pipa, palito, pia & \multirow{3}{*}{$\begin{array}{l}\text { pato, aluno, pena, } \\
\text { menina, nove, vela }\end{array}$} & \multirow{6}{*}{$\begin{array}{l}\text { pulo, tijolo, nova, } \\
\text { roda, sabiá, pifou, se- } \\
\text { mana, viola e feijoada }\end{array}$} \\
\hline & $\mathrm{N}$ & $\begin{array}{l}\text { nome, pena, menina, panela, neto, } \\
\text { aluno }\end{array}$ & & \\
\hline & $\mathrm{V}$ & nove, luva, novela, vovó, vela, violeta & & \\
\hline \multirow{3}{*}{$S, D, J$} & S & sapo, sofá, sala, sapato, sete, sabonete & \multirow{3}{*}{$\begin{array}{l}\text { sapo, sapato, dados, } \\
\text { roda, janela, jiló }\end{array}$} & \\
\hline & $\mathrm{D}$ & dado, roda, dia, salada, idade, data & & \\
\hline & $\mathrm{J}$ & sujo, juba, jiló, pajé, beijo, janela & & \\
\hline
\end{tabular}

\footnotetext{
${ }^{4}$ Nesse conjunto foram ensinadas apenas sílabas das consoantes c e g com as vogais a/o/u, pois as sílabas dessas consoantes com as vogais e/i são consideras como irregulares (GARCIA, 1995) e requerem ensino específico.
} 


\begin{tabular}{lllll}
\hline $\mathrm{X}, \mathrm{Z}$ & $\mathrm{X}$ & xale, lixo, peixe, roxo, faxina, taxa & lixo, peixe, xale, doze, \\
buzina, zebu & $\begin{array}{l}\text { zebu, buzina, azedo, doze,vazio, } \\
\text { beleza }\end{array}$ & $\begin{array}{l}\text { faixa, vexame, mexica- } \\
\text { no, beleza, come, vaca, } \\
\text { galo, pipoca, colega, } \\
\text { comigo }\end{array}$ \\
\hline $\begin{array}{l}\text { C, G } \\
(\mathbf{a}, \mathbf{o}, \mathbf{u})\end{array}$ & $\mathrm{C} \quad \begin{array}{l}\text { calo, faca, sacola, cueca, coxa, } \\
\text { abacaxi }\end{array}$ & $\begin{array}{l}\text { gato, goma, gula, fogo, bigode, } \\
\text { bexiga }\end{array}$ & $\begin{array}{l}\text { faca, sacola, cueca, gato, } \\
\text { bigode, fogo }\end{array}$ & \\
\cline { 2 - 5 } & $\mathrm{G}$ & & \\
\hline
\end{tabular}

Quadro 2 - Resumo geral dos procedimentos utilizados: Conjuntos de Sílabas, Grupos Silábicos, Palavras Utilizadas em Caderno e no Fichário, Figuras e Palavras Impressas Utilizadas nos Testes, Palavras de Recombinação

Fonte: elaboração própria

A primeira etapa, realizada em caderno, consistiu no ensino direto das sílabas do grupo silábico e de palavras compostas pelas sílabas ensinadas. A Figura 2 mostra a sequência do ensino: 1) apresentação, pela pesquisadora, da consoante escrita manualmente por canetinha preta (em letra maiúscula, fonte e tamanho aproximado: Arial, 90) e enquadrada por uma borda feita por canetinha azul; a pesquisadora dizia o fonema da consoante e pedia ao participante para repeti-lo. 2) Apresentação, pela pesquisadora, da vogal escrita por canetinha vermelha e enquadrada por uma borda feita por canetinha azul; o participante deveria nomear oralmente a vogal e quando ele não nomeava, a pesquisadora dizia o nome da vogal e pedia ao participante para repeti-lo. 3) Apresentação, pela pesquisadora, da sílaba formada pela consoante e pela vogal apresentadas anteriormente, sendo que a consoante era escrita por canetinha preta e a vogal por canetinha vermelha e ambas eram enquadradas por uma borda desenhada por canetinha azul; nesse momento a instrução da pesquisadora, simultaneamente à escrita das letras, era: "se eu pegar a letrinha (consoante) que tem o som (fonema) e juntar com a letrinha (vogal), vira (sílaba)", e o aprendiz deveria repetir oralmente o nome da sílaba ditada pela pesquisadora (o que caracterizava um treino para a emissão de comportamento ecóico ou de imitação vocal). 4) O ensino seguia essa sequência sucessivamente, vogal por vogal, até completar todas as vogais. 5) Após o ensino das sílabas com todas as vogais, o participante era instruído a apontar para cada uma das sílabas e nomeá-las na sequência ensinada (exemplo: ta, te, ti, to, tu); quando o participante apresentava 100\% de acertos na sequência ensinada, sem auxílio da pesquisadora, ele era instruído a nomear as sílabas em sequência aleatória (exemplo: tu, te, to, ta, ti) e, para isso, a pesquisadora apontava com a mão do participante para a sílaba a ser nomeada. Após apresentar 100\% de acertos na nomeação das sílabas em sequência aleatória, sem auxílio da pesquisadora, a folha do caderno era virada e as tentativas com palavras escritas eram iniciadas. 6) Na nova folha em branco, palavras formadas com as sílabas ensinadas eram escritas, mantendo-se o padrão de letras e cores: consoantes em preto, vogais em vermelho e bordas em azul. 7) No total eram escritas seis palavras por grupo silábico (ver Quadro 2) e o aprendiz deveria, simultaneamente, apontar para as sílabas de cada palavra e nomeá-las oralmente. Como as crianças aprendiam a nomear as sílabas, a tendência era que elas lessem as palavras com pausas entre as sílabas. Por isso, após a nomeaçáo realizada pelos participantes, a pesquisadora relia a palavra com fluência e pedia a eles para repetirem. Por exemplo: se a criança lia "ta e tu", a pesquisadora dizia: "agora vamos ler mais rápido, você leu tatu" (pareamento auditivo-visual direto). 
É importante ressaltar que à medida que as crianças passavam a apresentar maior fluência na leitura, a pesquisadora deixava de reler as palavras e passava a perguntar aos participantes "o que você leu?" para que eles dissessem o nome da palavra lida com fluência (não era requerido que eles indicassem o sentido da palavra lida). O critério para o término do ensino em caderno e o início da próxima etapa era de 100\% de acertos na nomeação das sílabas de todas as palavras, sem auxílio da pesquisadora, independente da fluência da leitura. Em todo o ensino respostas corretas eram consequenciadas por estímulos potencialmente reforçadores para cada um dos participantes e respostas incorretas eram seguidas de "não" e auxílio verbal para a correção.

A segunda etapa do ensino era realizada em fichário e consistia na apresentação de duas tentativas de emparelhamento multimodelo por identidade (ver GOMES; DE SOUZA, 2008). Cada tentativa era composta por três estímulos modelos e três estímulos de comparação apresentados simultaneamente. Os estímulos utilizados eram as palavras ensinadas anteriormente em caderno, porém impressas. Nessas tentativas, os estímulos modelo, que estavam fixados na página da direita do fichário, eram palavras impressas (letras maiúsculas, Arial, tamanho 72) com o padrão de cores utilizado anteriormente em caderno (consoantes em preto, vogais em vermelho, enquadradas por uma borda azul) e apresentavam pedaços de velcro expostos para que os estímulos de comparação fossem grudados sobre eles. Na página da esquerda estavam os estímulos de comparação, que eram móveis, apresentavam velcro na parte posterior, e consistiam em palavras idênticas às dos modelos, porém totalmente impressas na cor preta e sem bordas (letras maiúsculas, Arial, tamanho 72). A sequência de realização dessas tentativas era: 1) a pesquisadora instruía o participante a escolher um dos estímulos modelo; 2) o participante era instruído a nomear oralmente o estímulo modelo escolhido e a pesquisadora fornecia ajuda na fluência da leitura, quando necessário, semelhante ao ensino em caderno; 3) a pesquisadora perguntava: "onde está escrita a mesma coisa que você leu?” apontando em direção aos estímulos de comparação; 4) a criança selecionava a comparação referente ao modelo; 5) a pesquisadora instruía: "lê o que está escrito aí (comparação) e vê se é igual ao que você leu antes (modelo)"; 6) a criança lia oralmente o comparação e o colocava sobre seu respectivo modelo; 7) caso o participante acertasse, a pesquisadora consequênciava (com elogios e estímulos potencialmente reforçadores) e o instruía a selecionar o próximo estímulo modelo. Porém, se o participante errasse, a pesquisadora dizia "não" e auxiliava fisicamente na correção. $\mathrm{O}$ objetivo dessas tentativas era ensinar aos participantes que as palavras que eles liam em preto, vermelho e azul, poderiam ser lidas da mesma maneira se impressas apenas na cor preta. O critério para o término desse passo do ensino era de $100 \%$ de acertos em todas as relaçóes de identidade sem auxílio da pesquisadora.

A terceira etapa do ensino consistia na apresentação isolada de seis figuras, selecionadas para testes de cada conjunto silábico (ver Quadro 2), às quais o participante era ensinado a nomear oralmente; 1) a pesquisadora apresentava a figura e perguntava "que figura é essa?"; 2) caso o participante nomeasse corretamente a pesquisadora elogiava e passava para a próxima tentativa, porém se o participante não nomeasse ou nomeasse de maneira incorreta, a pesquisadora nomeava a figura e pedia ao participante para repetir oralmente o modelo. $\mathrm{O}$ critério para o término dessa etapa de ensino era de $100 \%$ de acertos na nomeação de todas as figuras, sem auxílio da pesquisadora, quando os participantes chegassem ao último grupo do conjunto silábico ensinado (composto por dois ou três grupos silábicos). Terminado o ensino e os testes em um grupo silábico, era iniciado o próximo grupo silábico. 
Antes do início do ensino de um grupo silábico novo, eram realizadas, por meio do caderno, tentativas de revisão dos grupos silábicos que consistiam na leitura oral das sílabas e das palavras escritas ensinadas anteriormente. Outra estratégia empregada para auxiliar na manutenção das sílabas aprendidas era o uso das sílabas ensinadas anteriormente no ensino de grupos silábicos novos. Por exemplo: após o ensino das sílabas de t, era iniciado o ensino com as sílabas de 1, que incluíam palavras que tinham sílabas de t e de 1 (ex. tela, lata, leite). As sílabas seguintes a serem ensinadas eram de $\mathrm{m}$; no treino do grupo $\mathrm{m}$ tinha palavras com sílabas de $\mathrm{t}$, le m (ex. tomate, muleta, mato, mola) e assim sucessivamente.

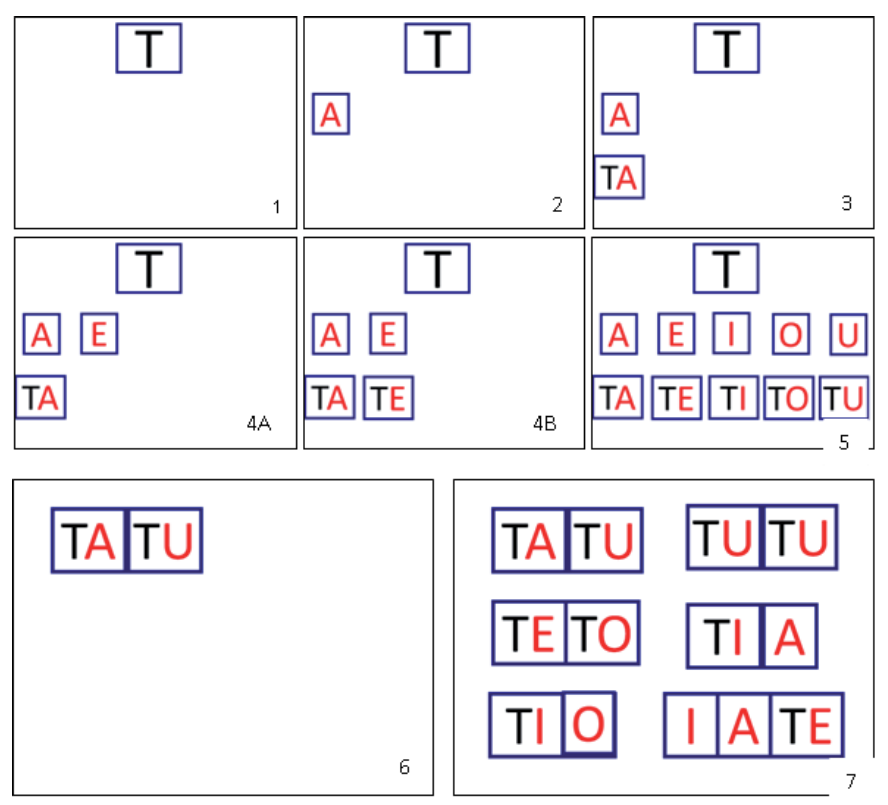

Figura 2 - Exemplo do primeiro passo do ensino realizado em caderno.

Legenda 1) consoante escrita manualmente em preto e enquadrada por borda azul; 2) primeira vogal escrita em vermelho enquadrada por borda azul; 3) apresentação da primeira sílaba: consoante em preto, vogal em vermelho e borda em azul; 4) apresentação da sílaba seguinte (A e B); 5) apresentação de todas as sílabas; 6) primeira palavra escrita com as sílabas ensinadas; 7) apresentação das seis palavras escritas com as sílabas ensinadas.

Fonte: elaboração própria

Em todas as atividades de ensino os acertos eram consequênciados com estímulos potencialmente reforçadores para cada um dos participantes. Para P1 foi utilizado um sistema de pontos e elogios; para P2 foram empregados brinquedos, figurinhas de desenhos animados, elogios e brincadeiras; e para P3 foi utilizado um sistema de pontuação que dava direito a assistir vídeos de desenhos animados na internet, brincadeiras e elogios. 


\section{Testes E Sondas}

Em cada conjunto silábico, antes do ensino das relaçôes C-D (nomeação de palavra impressa), por meio do ensino das sílabas, e B-D (nomeação de figura) nos grupos silábicos, os participantes eram expostos a tentativas de pré-teste com estímulos específicos para cada um dos conjuntos (ver Quadro 2). Esses testes eram realizados por meio de um caderno e por meio de fichas (palavras impressas, figuras e bases de papel; Ver Figura 1); todos os estímulos, exceto as figuras, eram apresentados na cor preta. No caderno, os estímulos eram escritos manualmente pela pesquisadora em letras maiúsculas (fonte e tamanho aproximado: Arial, 90), utilizando canetinha preta, e pretendiam avaliar, na seguinte sequência, se os participantes nomeavam oralmente: 1) as consoantes dos conjuntos silábicos que seriam ensinados (C-D: consoantes); 2) as vogais (C-D: vogais); 3) duas sílabas aleatórias de cada grupo silábico inserido no conjunto silábico a ser treinado (CD: sílabas); 4) as seis palavras selecionadas para o teste, constituídas por sílabas do conjunto silábico a ser ensinado (CD: palavras). Por meio de fichas eram verificadas as relações condicionais entre os estímulos da rede (ver Figura 1), na seguinte sequência: 1) C-D (nomeação de palavra impressa) e B-D (nomeação de figura), em tentativas nas quais os estímulos eram apresentados individualmente e o participante deveria nomeá-los oralmente; 2) B-C (figura-palavra impressa) e C-B (palavra impressa-figura), em tentativas de emparelhamento multimodelo com três estímulos modelos e três estímulos de comparação apresentados simultaneamente(ver Figura 1); 3) A-B (palavra ditada- figura) e A-C (palavra ditada-palavra impressa), em tentativas de emparelhamento com o modelo auditivo visual, no qual o estímulo auditivo era ditado pela pesquisadora e o participante deveria escolher entre três estímulos visuais apresentados simultaneamente (figuras ou palavras impressas, dependendo do tipo de tentativa), qual correspondia à palavra ditada. Após o ensino das relaçóes $\mathrm{C}-\mathrm{D}$ e B-D, os participantes realizavam tentativas de pós-teste C-D, B-D, B-C, C-B, A-C e A-B que eram idênticas às tentativas de pré-testes.

Sondas deleitura recombinativa foram realizadas antes dos participantes serem expostos ao ensino e aos testes dos Conjuntos 1, 3 e 5, que consistiam na apresentação isolada de dez palavras impressas formadas pelas sílabas recombinadas das palavras utilizadas no ensino dos conjuntos silábicos; o participante deveria ler oralmente cada uma das palavras. Após a realização dos Conjuntos silábicos 2, 4 e 6 os participantes executaram novamente tentativas de sondas de leitura recombinativa, que eram idênticas as sondasiniciais.

Nos testes e sondas, incentivos verbais e recompensas (figurinhas de desenhos animados) eram utilizados para favorecer a participação das crianças nessas tentativas, porém não eram contingentes a erros ou a acertos.

Todas as sessóes do experimento foram filmadas e o número de tentativas de ensino, acertos e erros dos participantes foi registrado pela pesquisadora durante as sessóes e conferido posteriormente a cada sessão, a partir das filmagens. Dois observadores independentes e ingênuos quanto ao propósito da pesquisa registraram 30\% das sessóes e o coeficiente de fidedignidade foi de $100 \%$. 


\section{Resultados e discussáo}

As Figuras 3, 4 e 5 apresentam o desempenho dos participantes nos testes dos conjuntos silábicos. Os testes foram realizados em caderno e por meio de fichas. No caderno foram avaliadas: a nomeação de consoantes (CD consoantes), de vogais (CD vogais), de sílabas (CD sílabas) e de palavras (CD palavras). Por meio de fichas foram avaliadas: a compreensão da leitura (BC, figuras-palavras impressas e $\mathrm{CB}$, palavras impressas-figuras); a nomeação de palavras impressas (CD) e de figuras (BD); e a identificação de palavras impressas (AC) e de figuras $(\mathrm{AB})$. As atividades de ensino foram realizadas em caderno, fichário e por meio de fichas (BD). Os resultados, no geral, foram semelhantes para os três participantes, tanto em testes quanto em ensino.

Nos testes observou-se que algumas relaçóes já se encontravam estabelecidas por ocasiâo dos pré-testes (nomeação de vogais $\mathrm{CD}$; nomeação de figuras $\mathrm{BD}$; identificação de figuras $\mathrm{AC}$ ) e tenderam a melhorar com o ensino. Em outras relaçóes, especialmente aquelas envolvidas na leitura oral de palavras (CD palavras e CD), na compreensão de leitura (BC e CB) e na identificação de palavras impressas (AC), os participantes apresentaram baixa porcentagem de acertos em pré-testes e obtiveram melhora acentuado do desempenho nos pós-testes.

O participante P2 apresentou baixa porcentagem de acertos em pós-testes de nomeação de consoantes (CD: consoantes) dos Conjuntos 1, 2 e 3, porém o desempenho foi melhor nos Conjuntos 4, 5 e 6; essa baixa porcentagem de acertos na nomeação das consoantes não é necessariamente um problema, já que o ensino enfatizava o fonema da consoante e não o nome da consoante, como era pedido nos testes. Outro aspecto importante a ser ressaltado a respeito dos resultados dos participantes refere-se ao desempenho discrepante de P2 e de P3 nos pós-testes das relaçóes CD (nomeação de palavras impressas) e AC (identificação de palavras impressas); apesar dos altos desempenhos nas tentativas CD, esses participantes apresentaram desempenhos baixos nas tentativas AC de quatro dos seis conjuntos silábicos (P2: 1, 2, 3 e 5; P3: 1, 2, 3 e 4).

Em relação ao processo de ensino, os participantes começaram respondendo com elevados escores de acertos e os poucos erros tenderam a ser superados. O ensino foi curto: P1 realizou um total de quinze sessóes de ensino, P2 realizou vinte e quatro e P3 realizou vinte e seis. Eram previstas, no mínimo, dezesseis sessóes de ensino, ou uma sessão pra cada grupo silábico (P1 realizou o ensino dos grupos silábicos c e g em uma única sessão).

A Figura 6 apresenta a porcentagem de acertos dos participantes em sondas de leitura recombinativa, que consistiam na apresentação isolada de palavras impressas novas, formadas pelas sílabas recombinadas das palavras utilizadas no ensino dos conjuntos silábicos. Observa-se aumento consistente na porcentagem de acertos dos participantes principalmente para P2 e P3.

Os resultados dos participantes indicaram que o procedimento utilizado favoreceu a aprendizagem e a manutenção da leitura combinatória com compreensão, com poucas sessóes de ensino e com baixo número de erros durante o processo.

O ensino direto das sílabas foi empregado buscando favorecer a leitura combinatória e, também, estabelecer a linha de base para a formação de classes de estímulos equivalentes e consequentemente para engendrar a leitura com compreensão. Foram utilizadas como estratégias de ensino: 1) a nomeação oral das consoantes (fonemas) e das vogais, além da leitura combinatória 
dos fonemas das consoantes com as vogais (sílabas) e de sílabas com outras sílabas (palavras), de maneira gradativa, partindo do mais simples para o mais complexo; 2) a apresentação estruturada dos estímulos visuais.

A nomeação oral de estímulos foi apontada em estudos sobre equivalência como uma variável que poderia favorecer a formação de classes por participantes com autismo (GOMES;VARELLA; DE SOUZA, 2010). Em relação à sequência gradativa do ensino, a literatura indica que pessoas com esse diagnóstico apresentam muitos déficits comportamentais distintos e que a aprendizagem de novas habilidades pode ocorrer mais facilmente quando os comportamentos são ensinados um a um, em pequenos passos (LOVAAS; SMITH, 1989).

O uso de estímulos visuais e a maneira como se apresentam nas tarefas, são apontados por muitos pesquisadores como variáveis relevantes para a aprendizagem de comportamentos novos por pessoas com autismo (MESIBOV;SCHOPLER; HEARSEY, 1994; PEETERS, 1998). O uso de cores diferentes para consoantes, vogais e bordas; a delimitação, por meio das bordas, da unidade intra-palavra a ser observada e nomeada; e a organização e a previsibilidade da sequência de apresentação dos estímulos, parecem ter favorecido a baixa ocorrência de erros e a aprendizagem dos participantes.

As tentativas de emparelhamento multimodelo por identidade entre palavras, impressas em cores e em preto, podem ter favorecido a generalização da leitura oral por similaridade, ou seja, parecem ter ensinado aos participantes a emitir a mesma resposta frente a estímulos semelhantes (CATANIA, 1999). A literatura indica que pessoas com autismo podem apresentar dificuldades em generalizar a aprendizagem e sugere que os procedimentos de ensino, planejados para essa população, devem prover estratégias para favorecer a generalização (PEETERS, 1998). Porém, apesar dos dados sugerirem que as tentativas de emparelhamento com o modelo favoreceram a generalização, como não foi realizada nenhuma avaliação que isolasse essa variável e medisse o desempenho dos participantes com ou sem a exposição a essas tentativas, não é possível afirmar que elas de fato favoreceram a generalização.

O treino silábico, a aprendizagem da leitura oral de palavras impressas em preto (CD) e os treinos de nomeação de figuras (BD), com a nomeação (D) em comum, permitiram estabelecer a linha de base para a emergência das relaçóes entre figuras e palavras impressas (BC) e entre palavras impressas e figuras (CB), que apresentaram as propriedades de simetria e de transitividade, necessárias à equivalência de estímulos (SIDMAN, 1994) e que caracterizaram a leitura com compreensão.

Apesar da alta porcentagem de acertos apresentada pelos participantes nos pós-testes de leitura oral (CD), de leitura com compreensão (BC e CB) e de nomeação oral de figuras (BD), os participantes P1 e P2 obtiveram baixa porcentagem de acertos nas tentativas auditivo-visuais de identificação de palavras impressas (A-C), em quatro dos seis conjuntos silábicos. Isso pode ter ocorrido em função de dificuldades na aprendizagem de relaçóes auditivo-visuais apresentadas por pessoas com autismo, relatadas pela literatura especializada (MESIBOV;SCHOPLER; HEARSEY, 1994), como pode ser resultado do procedimento utilizado, que não ensinou de maneira sistemáticaqualquer relação auditivo-visual, o que possivelmente não favoreceu a precisão dos participantes nesse tipo de tentativa. 

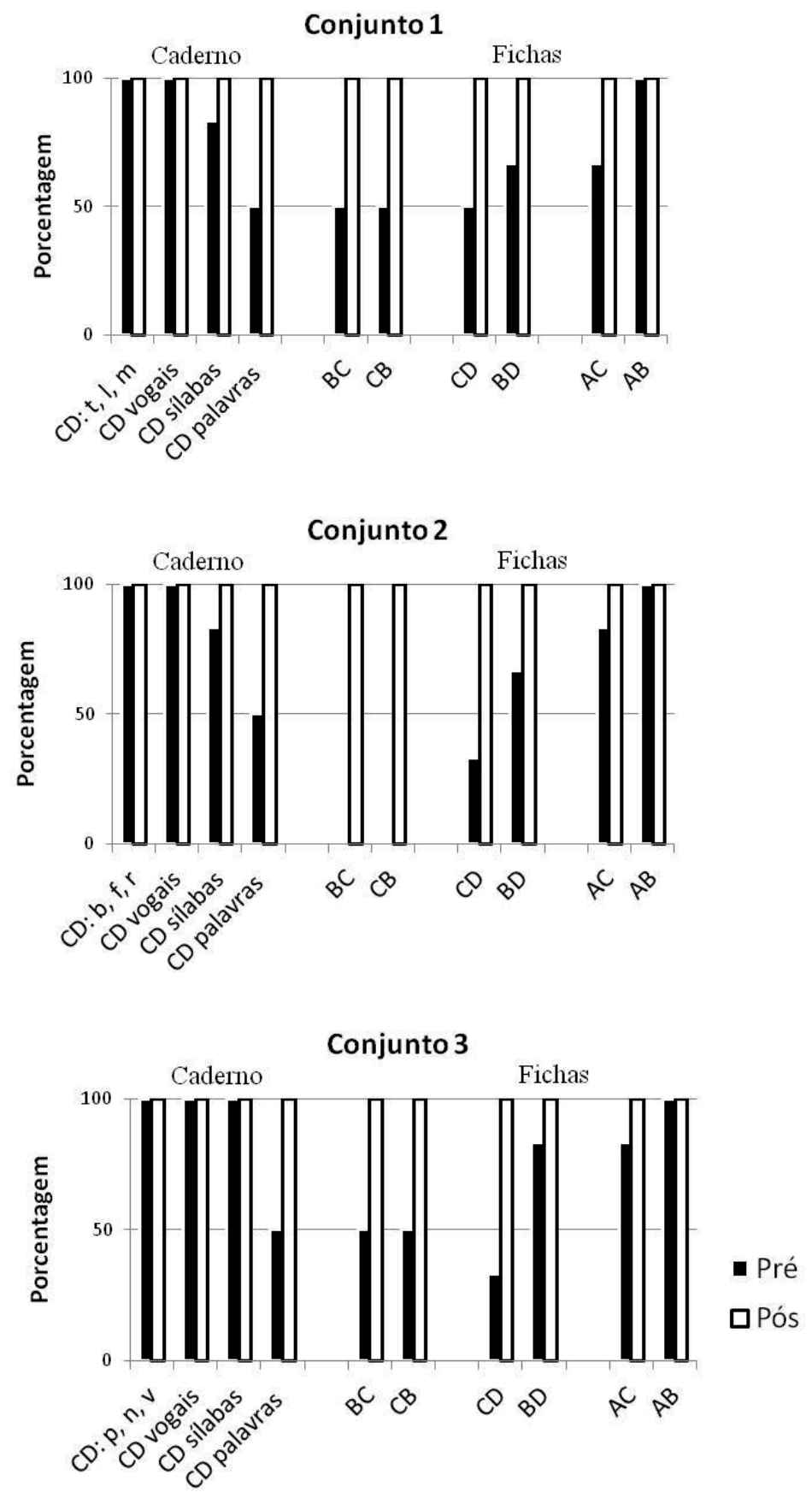

Figura 3 - Porcentagem de acertos de P1 em pré e pós-testes realizados em caderno e por meio de fichas nos Conjuntos 1 a 3 .

Fonte: elaboração própria 

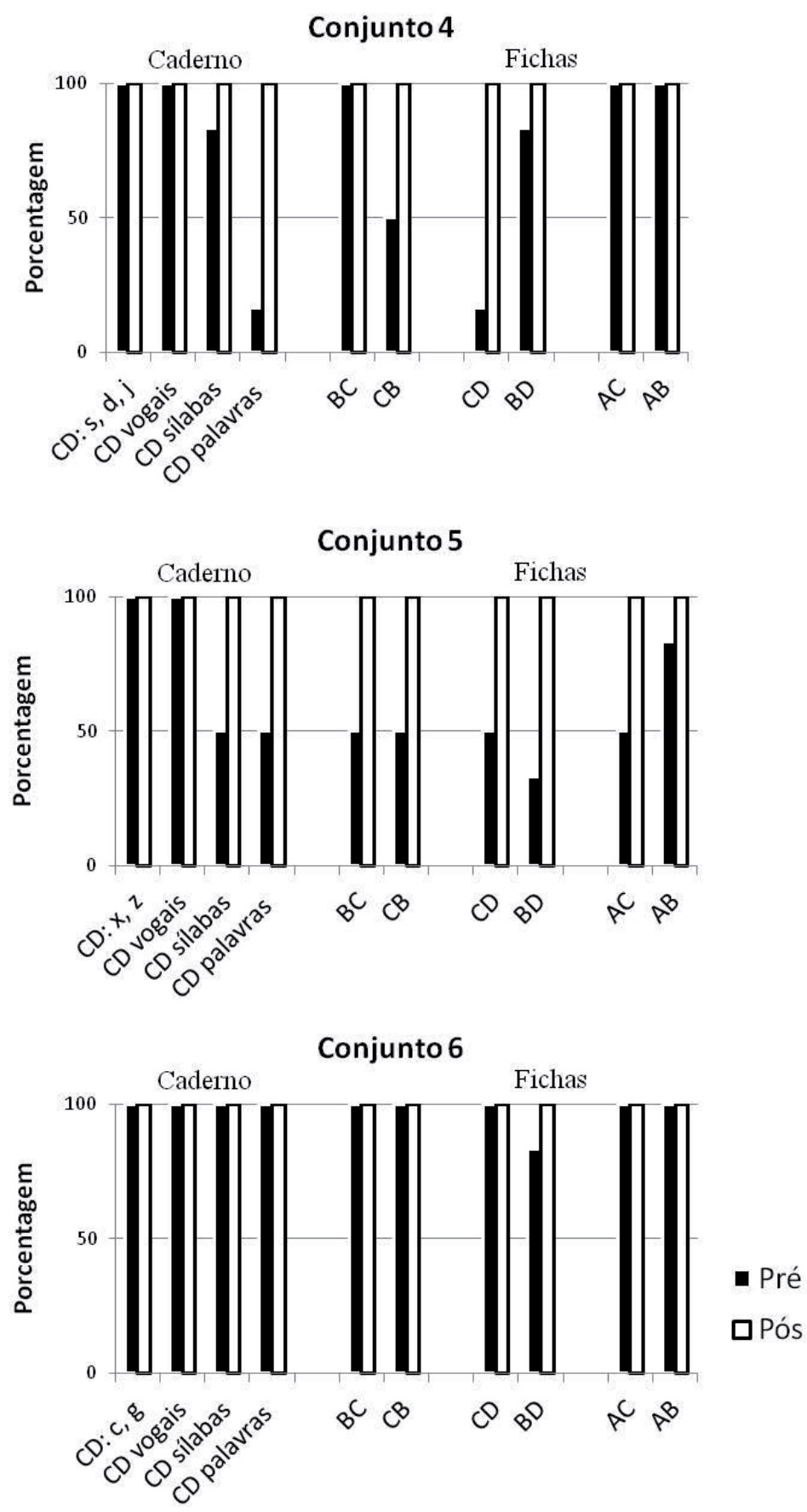

Figura 3 - Porcentagem de acertos de P1 em pré e pós-testes realizados em caderno e por meio de fichas nos Conjuntos 4 a 6 (continuação).

Fonte: elaboração própria 

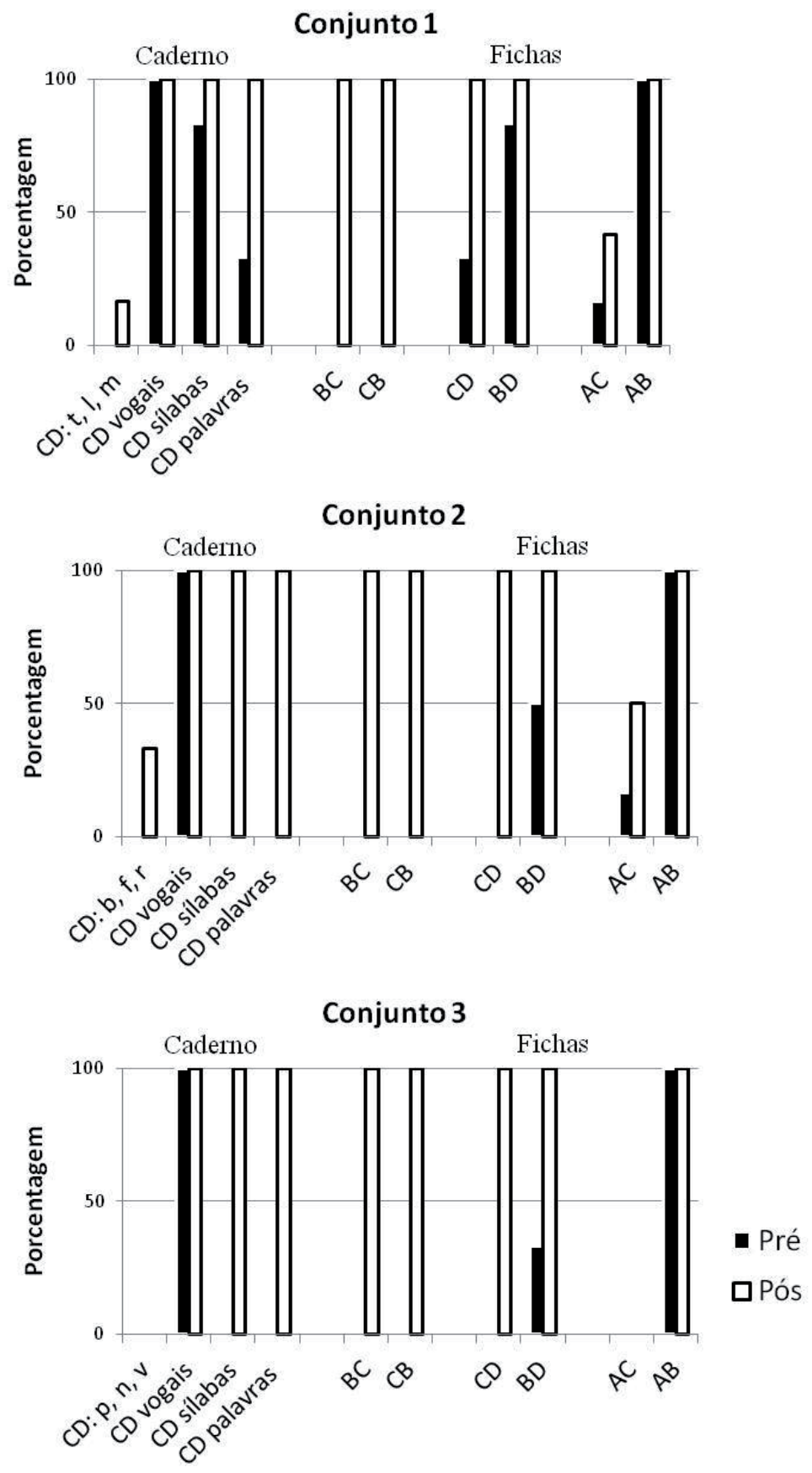

Figura 4 - Porcentagem de acertos de P2 em pré e pós-testes realizados em caderno e por meio de fichas nos Conjuntos 1 a 3 .

Fonte: elaboração própria 

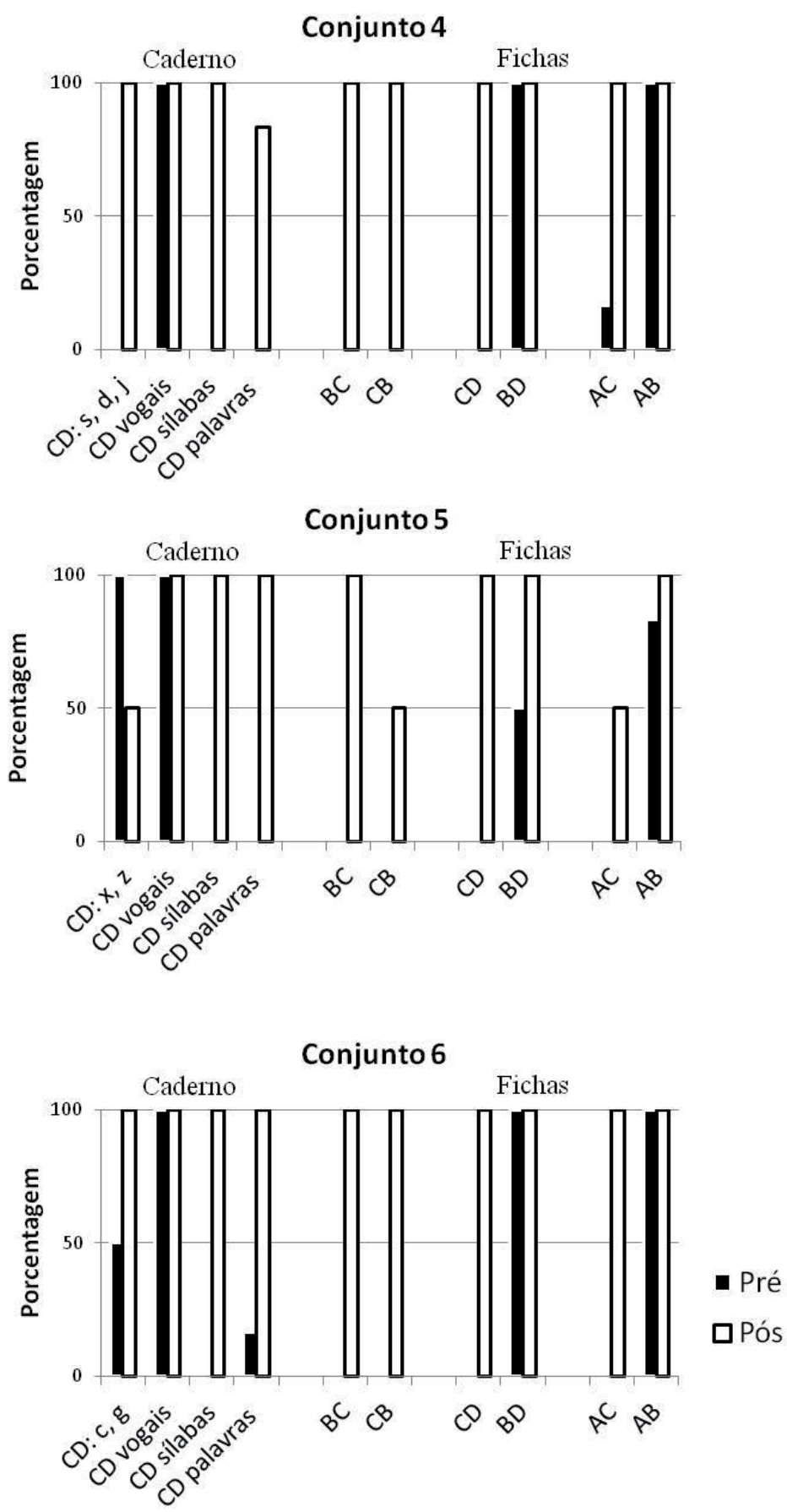

Figura 4 - Porcentagem de acertos de P2 em pré e pós-testes realizados em caderno e por meio de fichas nos Conjuntos 4 a 6 (continuação).

Fonte: elaboração própria 

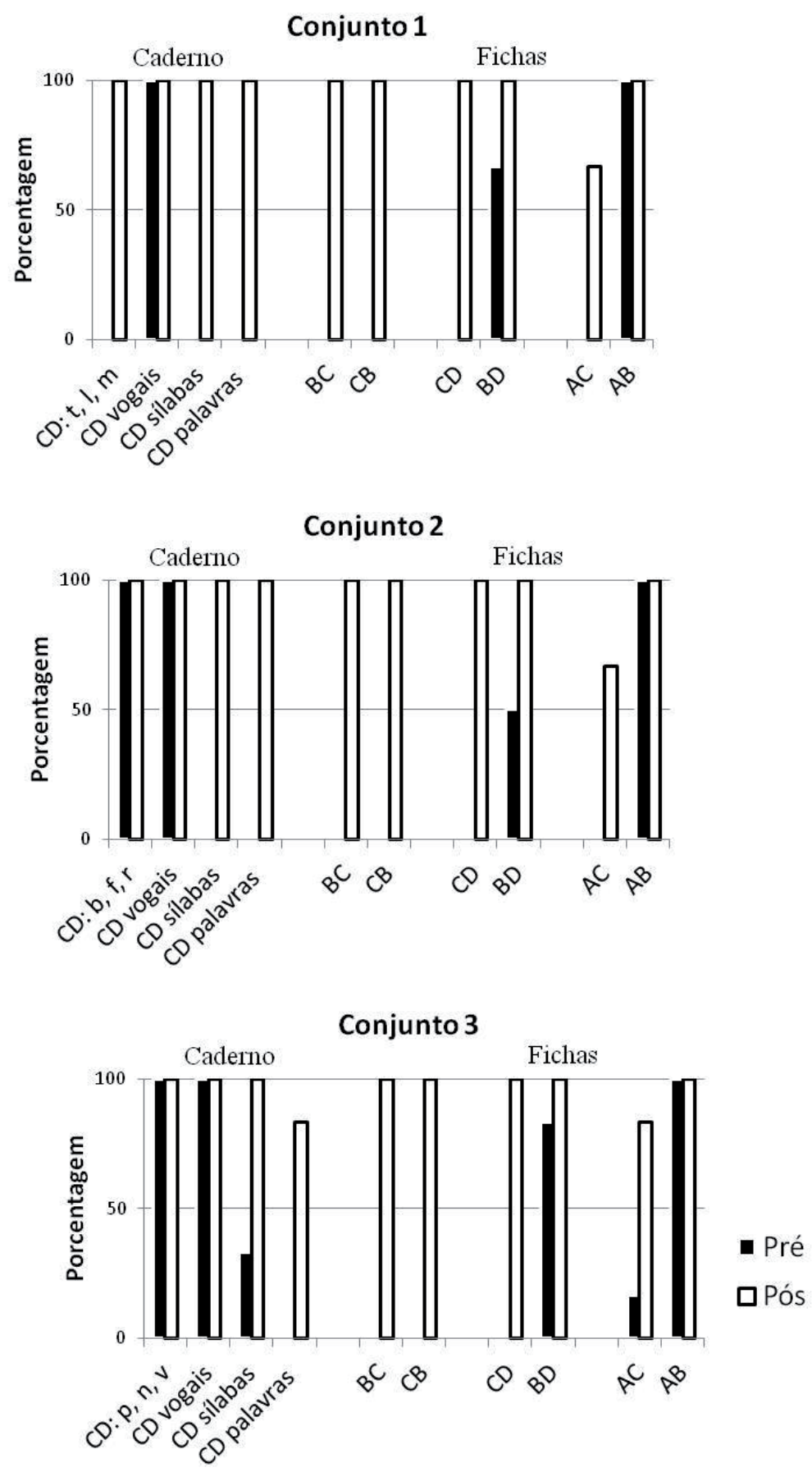

Figura 5 - Porcentagem de acertos de P3 em pré e pós-testes realizados em caderno e por meio de fichas nos Conjuntos 1 a 3 .

Fonte: elaboração própria 

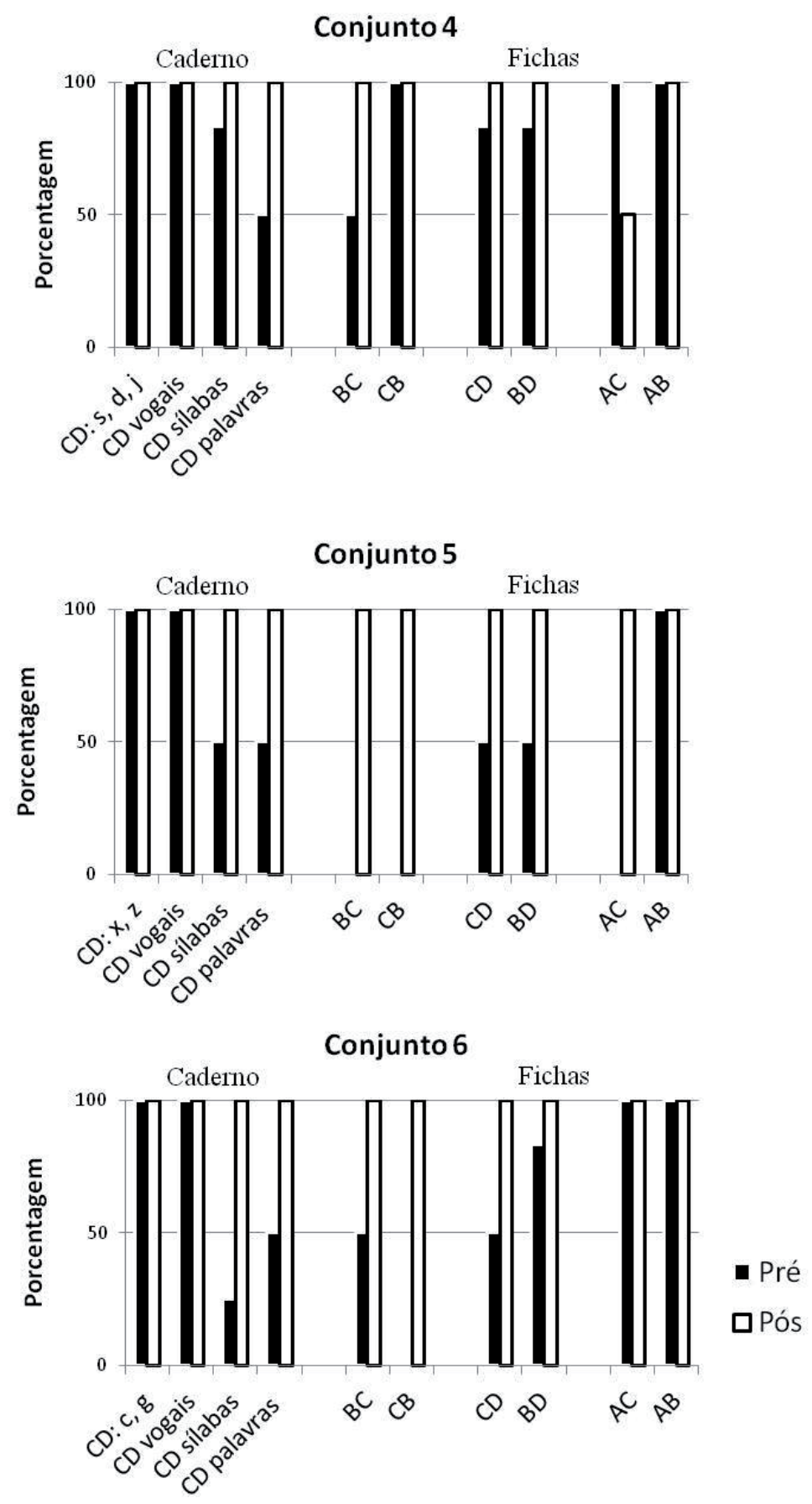

Figura 5 - Porcentagem de acertos de $\mathrm{P} 3$ em pré e pós-testes realizados em caderno e por meio de fichas nos Conjuntos 4 a 6 (continuaçáo).

Fonte: elaboração própria 
P1

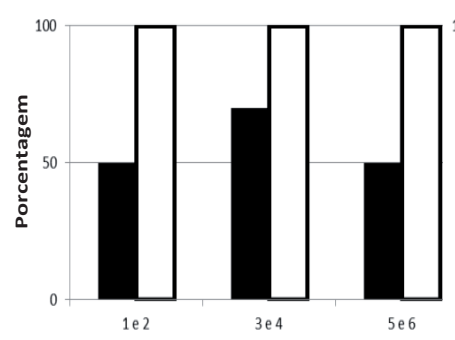

P2

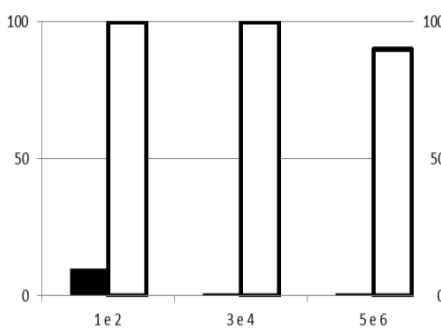

P3

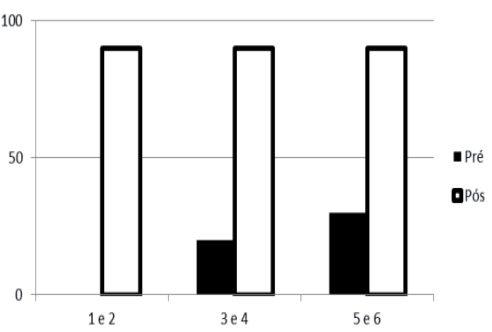

Figura 6 - Porcentagem de acertos dos participantes individuais em sondas de leitura recombinava. Fonte: elaboração própria

\section{Coclusão}

Pode-se concluir que o procedimento de ensino foi efetivo para promover a aprendizagem de leitura combinatória com compreensão pelos participantes com autismo, com poucas sessóes de ensino (15 a 26) e com baixo número de erros durante o ensino (SIDMAN, 1985). O baixo custo do material utilizado (caderno, canetinhas, figuras, palavras impressas, fichário e velcro) e o número reduzido de sessóes de ensino sugerem que o procedimento descrito nesse estudo possa ser um recurso viável ao professor da escola comum no processo de alfabetização de seus alunos com autismo. Porém, é importante ressaltar que os participantes desse estudo tinham autismo leve/ moderado, eram falantes e capazes de nomear pelos menos as vogais, antes do início do experimento. Portanto, os resultados desse estudo muito provavelmente não podem ser generalizados para pessoas com autismo grave e não falantes.

A natureza dos dados obtidos no presente estudo e o estágio de desenvolvimento do repertório comportamental dos participantes que geraram esses resultados sugerem fortemente a necessidade de uma avaliação mais ampla, com participantes com outros repertórios ou em outras situaçóes de ensino, como a sala de aula da escola comum. Seria importante, também, que o estudo fosse replicado com um delineamento que permitisse acompanhar o desempenho dos participantes ao longo de todo o procedimento de ensino, em relação à aprendizagem dos grupos silábicos, antes que eles fossem ensinados, durante e após o ensino, como no caso do delineamento de linha de base múltipla.

\section{REFERÊNCIAS}

ADAMS, M.J. Beginning to read. Cambridge: MIT Press, 1994.

ALVES, K.R. et al. Leitura recombinativa em pessoas com necessidades educacionais especiais: análise do controle parcial pelas sílabas. Psicologia: Teoria e Pesquisa, Brasília,v.23, n.4, p.387-398, 2007.

AMERICAN PSYCHIATRIC ASSOCIATION. Diagnostic and statistical manual of mental disorders DSM-5. Washington: APA; 2013.

CATANIA, A.C. Aprendizagem: comportamento, linguagem e cognição. Porto Alegre: Art Med, 1999. 
DE ROSE, J.C.; DE SOUZA, D.G.; HANNA, E.S. Teaching reading and spelling: exclusion and stimulus equivalence. Journal of Applied Behavior Analysis, v.29, p.451-469, 1996.

DE SOUZA, D.G. et al. Teaching generative reading via recombination of minimal textual units: a legacy of Verbal Behavior to children in Brazil. International Journal of Psychology and Psychological Therapy, v.9, n.1, p.19-44, 2009.

GARCIA, R.C. A toca do tatu: manual do professor. São Paulo: Saraiva, 1995.

GOMES, C.G.; DE SOUZA, D.G. Desempenho de pessoas com autismo em tarefas de emparelhamento com o modelo por identidade: efeitos da organização dos estímulos. Psicologia: Reflexão e Crítica, Porto Alegre, v.21, n.3, p.412-423, 2008.

GOMES, C.G.; VARELLA, A.A.; DE SOUZA, D.G. Equivalência de estímulos e autismo: uma revisão de estudos empíricos. Psicologia Teoria e Pesquisa, Brasília,v. 26, n.4, p.729-737, 2010.

GRIGORENKO E.L. et al. A descriptive study of hyperlexia in a clinically referred sample of children with developmental delays.Journal of Autism and Developmental Disorders, v.32, n.1, p.3-11, 2002.

HANNA, E.S. et al. Leitura recombinativa de pseudopalavras impressas em pseudo-alfabeto: similaridade entre palavras e extensão da unidade ensinada.Psicologia USP, São Paulo, v.21, n.2, p.275$311,2010$.

KERR, N. et al. The measurement of motor, visual and auditory discrimination skills. Rehabilitation Psychology, v.24, n.3, p.95-112, 1977.

LEON, V.C. et al. Propriedades psicométricas do perfil psicoeducacional revisado: PEP-R. Avaliação Psicológica, v.3, n.1, p.39-52, 2004.

LOVAAS, O.I.; SMITH, T. A comprehensive behavioral theory of autistic children: Paradigm for research and treatment. Journal of Behavior Therapy and Experimental Psychiatry, v.20, n.1, p.1729,1989.

MESIBOV, G.B; SCHOPLER, E.; HEARSEY, A. Structured teaching. In: SCHOPLER, E.; MESIBOV, G. (Eds.). Behavior issues in autism. New York: Plenum Press, 1994, p.195-210.

MUELLER, M.M.; OLMI, D.J.; SAUNDERS, K.J. Recombinative generalization of within-syllable units in pre reading children. Journal of Applied Behavior Analysis, v.33, n.4, p.515-531, 2000.

NATION, K. et al. Patterns of reading ability in children with autism spectrum disorder. Journal of Autism and Developmental Disorders, v.36, n.7, p.911-919, 2006.

O'CONNOR, I.M.; KLEIN, P.D. Exploration of strategies for facilitating the reading comprehension of high-functioning students with autism spectrum disorders.Journal of Autismand Developmental Disorders, v.34, n.4, p.115-127, 2004.

PEETERS, T. Autismo: entendimento teórico e intervenção educacional. Rio de Janeiro: Cultura Médica, 1998.

PEREIRA, A.; RIESGO, R.S.; WAGNER, M.B. Autismo infantil: tradução e validação da Childhood Autism Rating Scale para uso no Brasil. Jornal de Pediatria, Rio de Janeiro, v.84, n.6, p.487-494, 2008.

SCHOPLER, E. et al. Individualized assessment and treatment for autistic and developmentally disabled children: Psychoeducational profile-revised (PEP-R). Austin: PRO-ED, 1990.

SCHOPLER, E.; REICHLER, J.; RENNER, C. CARS-The Childhood Autism Rating Scale. Los Angeles: Westerm Pychological Services, 1998. 
GOMES, C.G.S. \& DE SOUZA, D.G.

SEREJO, P. et al. Leitura e repertório recombinativo: efeito da quantidade de treino e da composição dos estímulos. Revista Brasileira de Análise do Comportamento,v.3, n.2, p.191-215, 2007.

SIDMAN, M. Aprendizagem-sem-erros e sua importância para o ensino do deficiente mental. Psicologia, v.11, n.3, p.1-15, 1985.

SIDMAN, M. Equivalence relations and behavior: a research story. Boston: Authors Cooperative, 1994.

Recebido em: 21/05/2015

Reformulado em: 10/04/2016

Aprovado em: 29/04/2016 